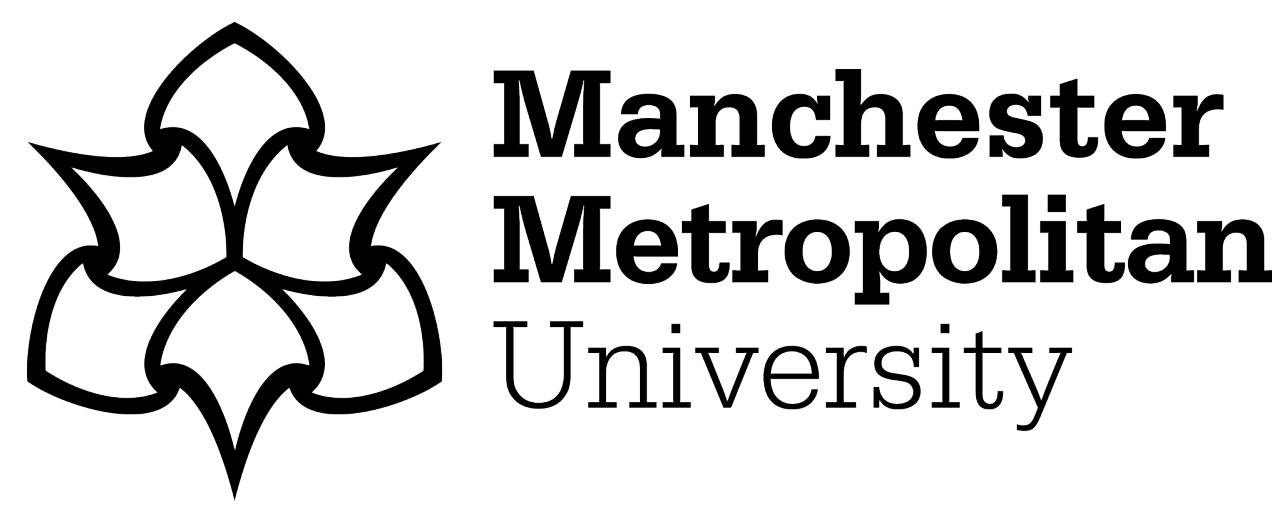

Gosling, Paul Christopher and Symeonakis, Elias ORCID logoORCID: https://orcid.org/0000-0003-1724-2869 (2020) Automated map projection selection for GIS. Cartography and Geographic Information Science, 47 (3). pp. 261-276. ISSN 1523-0406

Downloaded from: https://e-space.mmu.ac.uk/625303/

Version: Accepted Version

Publisher: Informa UK Limited

DOI: https://doi.org/10.1080/15230406.2020.1717379

Please cite the published version 


\section{Automated map projection selection for GIS}

Paul Christopher Gosling, Elias Symeonakis

UNIGIS, Manchester Metropolitan University, Manchester, United Kingdom

pcgosling@outlook.com 


\section{Automated map projection selection for GIS}

The selection of an appropriate map projection has a fundamental impact on the visualization and analysis of geographic information. Distortion is inevitable and the decision requires simultaneous consideration of several different factors; a process which can be confusing for many cartographers and GIS users. The last few decades have seen numerous attempts to create automated map projection selection solutions based on traditional classification and selection guidelines, but there are no existing tools directly accessible to users of GIS software when making projection selection decisions. This paper outlines key elements of projection selection and distortion theory, critically reviews the previous solutions, and introduces a new tool developed for ESRI's ArcGIS, employing an original selection method tailored to the specific purpose and geographical footprint characteristics of a GIS project. The tool incorporates novel quantitative projection distortion measures which are currently unavailable within existing GIS packages. Parameters are optimized for certain projections to further reduce distortions. A set of candidate projected coordinate systems are generated that can be applied to the GIS project; enabling a qualitative visual assessment to facilitate the final user selection. The proposed tool provides a straightforward application which improves understanding of the projection selection process and assists users in making more effective use of GIS.

Keywords: projection; selection; distortion; shape distortion; areal distortion; distance distortion 


\section{Introduction}

Projection selection is the cartographic process of determining the most appropriate map projection for a particular geographic application, and is one of the fundamental problems which must be solved by cartographers to determine a map's graphical framework and scale distortion characteristics (Robinson, 1974). The map projection discipline is recognized as one of the most challenging in Geography (Olson, 2006), and choosing a suitable projection continues to be complicated and overwhelming for experienced and novice map-makers alike (De Genst \& Canters, 1996; Kimerling, Buckley, Muehrcke, \& Muehrcke, 2012; Snyder, 1993). The particular map purpose should be defined by the cartographer before assessing different projection choices (Hsu, 1981); however there is no single optimal solution to the problem (Canters, 2002; Snyder, 1987).

Distribution of map projection distortion has a significant impact on planned map use (Snyder \& Voxland, 1989). Patterns vary between projections and whilst distortion is inevitable and suggests something undesirable it can also be viewed positively as providing design flexibility for the cartographer (Robinson, 1988). The selection process is predominantly concerned with arranging the geographical zone of interest to coincide with the least amount of distortion (Hsu, 1981), determined by the "location, size and shape of the area to be mapped" (Maling, 1992, p.224). Although prior authors used the term 'area' to refer to the zone of coverage, this article will reserve the word 'area' for the measurement of two-dimensional extent, and major issue in distortions caused by projections. The zone of interest will be termed 'footprint'. As footprint area increases a greater proportion of the Earth's curvature is displayed and a higher degree of distortion becomes apparent. Footprint area is therefore directly related to the significance of the selection decision and is especially relevant for maps covering 
a hemisphere or the entire world (Hsu, 1981; Maling, 1992; Robinson, 1974; Slocum, McMaster, Kessler, \& Howard, 2010). Distortion characteristics should be considered alongside projection properties which may be beneficial for a particular requirement together with aesthetic considerations such as the graticule appearance (Bugayevskiy \& Snyder, 1995; Canters, 2002; Canters \& Decleir, 1989).

Projection selection influences effective GIS use (Eldrendaly, 2006). Currently, there are no existing tools within GIS packages that assist users when making projection selection choices. GIS users do not necessarily have sufficient experience (Canters, 2002) or adequate education (Mulcahy \& Clarke, 2001) despite the increasing need to understand projection concepts (Kessler, 2018), making it easy for inappropriate default options to be chosen (Šavrič, Jenny, \& Jenny, 2016) and increasing the risk of errors being made without potential problems being recognized (Canters, 2002; Nyerges \& Jankowski, 1989). There are also no existing tools within GIS software which calculate or visualize projection distortion properties, something that would improve user understanding of distortion patterns and the valuable role this plays in the selection process (Chrisman, 2017; Mulcahy \& Clarke, 2001; Slocum et al., 2010).

Human thought processes can assess the different options and determine the appropriate selection for a particular map design (Smith \& Snyder, 1988), but well defined tools can aid novice users in making suitable choices (De Genst \& Canters, 1996). Projection selection is a good candidate for an automated system by transferring and organizing human knowledge into programmed rules (Jankowski \& Nyerges, 1989), helping cartographers overcome obstacles with the complicated selection process and ensuring efficient use of available projections (Snyder, 1993).

Within this framework, this paper describes the creation of a new projection selection methodology. The primary difficulties in the selection process are first 
evaluated, previous technical solutions are reviewed, and the development of an automated projection selection tool for GIS, designed to assist cartographers in making appropriate decisions and achieving more effective use of GIS, is presented. Significant benefits could be realized by incorporating the tool within GIS, as this would enable improved handling of the geographic footprint and allow users to directly view candidate projection results for their specific project prior to final selection.

\section{Background}

\section{Selection difficulties}

Treating projection selection in an organized way is challenging due to the cartographer needing to simultaneously consider and make compromises among several inter-related elements (Jankowski \& Nyerges, 1989; Zhao, Zhu, Li, \& Xing, 2007). Tyner (2010) specifies 'Projections' as one of eight elements of the map design process, and with each of its sub-elements directly related to the other seven elements the significant impact of projection selection on cartographic decision-making is evident. The number and variety of projections available complicates the process (Canters, 2002; Nyerges \& Jankowski, 1989; Snyder, 1987), especially for world maps where many were designed to solve mathematical problems rather than addressing particular practical uses (Robinson, 1974).

Map-makers can utilize projection classification schemes grouping candidates by geometrical construction, graticule shape, special properties, or parameters (Canters, 2002; Maling, 1992; Snyder, 1987; Tobler, 1962), or directories describing popular projections and visualizing graticule characteristics and distortion properties (Snyder, 1987; Canters \& Decleir, 1989; Snyder \& Voxland, 1989). However, using a classification scheme may result in several options with no routine process for making 
the final decision (De Genst \& Canters, 1996). Snyder (1987) published a detailed list of projection recommendations covering various purposes based on geographic footprint characteristics, distortion properties, and other relevant projection features. Snyder's guidelines are generally described as the clearest and most detailed available (Nyerges \& Jankowski, 1989; Slocum et al., 2010), though using these and other classification schemes can be conceptually problematic as the cartographer is responsible for the counter-intuitive determination of the distortion property most suitable for the map purpose (Canters, 2002; Mekenkamp, 1990; Nyerges \& Jankowski, 1989).

Recognizing and accounting for projection distortion is difficult, even for those with knowledge of the subject (Battersby, 2009). Most people experience and naturally view the Earth as flat (Carbon, 2010; Egenhofer and Mark, 1995), intuitively using twodimensional Euclidean geometry which is taught from a young age (Tobler, 1993). The Earth can effectively be described as a two-dimensional surface (Tobler, 2008), and maps are often treated as if there was no distortion with scale incorrectly assumed to be constant across the entire map (Maling, 1989; Maling, 1992). Chrisman (2017, p. 641) refers to this as "some kind of collective amnesia". Developing expertise of complex projection concepts requires instruction to improve cognitive skills (Downs \& Liben, 1991), but despite a large body of literature little has been achieved in educating general map users (Olson, 2006), and most do not possess the advanced understanding that maps are a representation of all or part of the Earth's surface using spherical nonEuclidean geometry (Anderson \& Leinhardt, 2002; Kimerling et al., 2012). Maps and GIS display geographic space, but users interact with them in what is called manipulable space and dealing with these two scales simultaneously is confusing (Mark and Freundschuh, 1995). These cognitive difficulties are presumably the primary reason 
why inexperienced cartographers find the map projection selection process complex and confusing.

The original choice of the map as the basis for GIS was sensible given the technology limitations, but this legacy may be limiting as advanced analysis and modelling processes are often map-based and there is little evidence of adoption of globe-based methods for measuring distance or calculating area (Chrisman, 2017; Goodchild, 2018). An elementary mistake made by some GIS users is displaying geographic data without selecting a projection, a practice which is easy but unacceptable (Tyner, 2010) and generally compared to using the Plate Carrée projection (Chrisman, 2017). This approach can lead to erroneously using latitude and longitude as planar coordinates, even though distances and areas calculated using degree units are clearly meaningless (Chrisman, 2017; Hunter \& Reinke, 2000; Longley, Goodchild, Maguire, \& Rhind, 2011).

GIS technology removes the difficulty of working manually with map projections, but increases the need for users handling digital geographic data to develop greater understanding of the influence of datums, ellipsoids and projections on analysis and mapping (Kessler, 2018). Projection selection can therefore be seen in a wider context of the overall difficulties perceiving distortion and the general problem of misunderstanding how geographic information is managed, analysed and displayed using GIS. This potentially leads to confusion and errors when making selection decisions and numerous authors over recent decades have been motivated to develop automated solutions.

\section{Previous solutions}

Most existing projection selection tools are standalone research projects, some described as being unfinished (Snyder, 1993) with the Projection Wizard (Šavrič, Jenny 
et al., 2016) the only easily accessible solution (http://projectionwizard.org/). All known solutions follow similar general principles primarily based on Snyder's selection guidelines. Two previous efforts to develop ESRI ArcGIS applications include map purpose as an input (Eldrendaly, 2006; Zhao et al., 2007), but these are unavailable and not fully integrated with the geographic objects. Most solutions ask questions for the desired projection distortion and geometric properties as a surrogate for purpose, which will be difficult to answer and displays the counter-intuitive nature of selection guidelines previously highlighted. Unambiguously answering geographical footprint input questions is also challenging. Mekenkamp (2005) suggests a visual approach using a globe, but requires successfully identifying area footprint as circular, rectangular or triangular. Jankowski \& Nyerges (1989) use a knowledge-base to capture answers for geographical entities, thus potentially replicating incorrect responses for future selections. Recent solutions incorporate a map view to define the footprint (Finn et al., 2004; Šavrič, Jenny et al., 2016), but these tools use a simple geographic 'rectangle' and selecting complicated shapes is impossible.

Limiting the number of available projections has been recognized by several solutions to reduce confusion (De Genst \& Canters, 1996), streamline implementation (Canters, 2002) and provide a straightforward user selection process (Šavrič, Jenny et al., 2016). Perspective projections are suitable for continental and smaller footprints if flexible parameter optimization is available (Canters, 1991), an approach favored by Mekenkamp (1990), but as these introduce excessive distortion at global scales it is also necessary to expand the range of available projections to include those designed for world maps (De Genst \& Canters, 1996). The specific distortion difficulties associated with raster data are only considered by the USGS Decision Support System (Finn, Usery, Posch, \& Seong, 2004). 
The Interactive Map Projections system (Brainerd \& Pang, 2001), the web-based decision support system for choosing appropriate map projections (http://mercator.elte.hu/ kerkovits/projections/) (Kerkovits \& Gede, 2017) and the commercial 'Geocart 3' software (https://www.mapthematics.com/) focus on aiding selection by displaying distortion information to improve projection properties understanding. Many projects discuss distortion assessment principles but only Ivanov \& Zagrebin (2011) combine both selection and distortion visualization capabilities. The most comprehensive solution for distortion reduction is by De Genst \& Canters (1996), including parameter optimization and presentation of mean finite scale distortion index. The Projection Wizard uses this index to rank world map options (Šavrič, Jenny et al., 2016).

No single existing solution fully incorporates both key selection elements of purpose and geographic footprint characteristics, whilst also including methods for distortion reduction and visualization. Šavrič, Jenny et al. (2016) conclude by suggesting that the Projection Wizard could be a stepping stone to the future development of an automated map projection selection process for GIS.

\section{Purpose of application guides projection selection}

The importance of the application's purpose to selection has been highlighted, together with the absence in existing guidelines and automated solutions. A comprehensive study of the relationship between purpose and projection properties is recommended to improve applicability (Canters, 2002), so this section aims to review sources to enable development of a conceptual model for implementing an automated selection scheme primarily based on the purpose.

The globe is the only representation of the Earth which shows shapes, relative sizes and distances correctly, but only half of the Earth can be seen at once (Hruby \& 
Riedl, 2018) and maps have advantages in terms of cost and ease of manufacture, replication and use, and with simplifying cartometric measurements (Goodchild, 2018; Slocum et al., 2010). There are two primary map types: (i) general reference, displaying geographical feature locations, e.g. topographic, road, and atlas maps; (ii) thematic, displaying distribution patterns of geographic attributes which do not generally physically exist and are sometimes referred to as statistical maps (Dent, 1999; Kimerling et al., 2012; Slocum et al., 2010).

Numerous options exist for general reference world maps. The Robinson projection, originally developed for Rand McNally (Robinson, 1974), was subsequently adopted by the US National Geographic Society before later replacement by the Winkel-Tripel (Kessler, 2000). Winkel-Tripel is favored by The Times Atlas (The Times, 2014) and performs well in the comprehensive finite distortion assessment by Canters (2002) and distortion study by Goldberg \& Gott (2007). Potential alternatives are the Natural Earth projections designed using a subjective graphical approach similar to Robinson, with the original version performing slightly better in a user study (Šavrič, Jenny, Patterson, Petrovic, \& Hurni, 2011; Šavrič, Patterson, \& Jenny, 2016). For other footprint extents, the selection guidelines by Snyder (1987) provide a baseline, together with the recommendation of the equidistant property as a compromise between conformal and equal-area extremes (Maling, 1992), and Bonne for mapping countries and continents with a North-South extent (Dent, 1999). The Sinusoidal projection is the Equatorial aspect of the Bonne and therefore an alternative for those regions.

For thematic maps the equal-area property is recommended as area may be important to the data being mapped, e.g. population density (Dent, 1999). Maling (1992) shows a single recommendation of this property for statistical distribution maps, and determining appropriate selections based on footprint area and extent using Snyder 
(1987) is straightforward. Additional options include Mollweide, Hammer and Boggs Eumorphic for world maps, and Bonne, Lambert Azimuthal Equal-Area, Albers and Sinusoidal for continents or smaller footprints (Dent, 1999; Slocum et al., 2010).

Studies investigating raster data re-projection also focus on the equal-area property as analysis is based on image pixel area rather than shape or distance (Steinwand, Hutchison, \& Snyder, 1995). For global applications, Interrupted GoodeHomolosine is visually appealing and valid for analysis due to favorable distortion properties (Steinwand, 1994). Steinwand et al. (1995) recommends Interrupted Mollweide where either land or ocean are not required, Wagner IV or Wagner VII for uninterrupted applications, and Lambert Azimuthal Equal-Area for hemisphere and continental uses. Other suggestions include uninterrupted Mollweide (Usery \& Seong, 2000) and Sinusoidal (Seong, Mulcahy, \& Usery, 2002; Seong \& Usery, 2003; White, 2006), although these papers focus on data management rather than GIS analysis.

Navigation charts require preservation of certain special properties to enable the vessel or aircraft to understand the relationship between the start and end points in terms of shortest distance (a great circle arc or geodesic) or by following a line of constant bearing (rhumb-line or loxodrome) (Maling, 1992). For aeronautical navigation Lambert Conformal Conic is preferred as great circles are shown approximately as straight lines and distances can be measured more accurately, and for polar navigation the polar aspect of the Stereographic is traditionally used (Maling, 1992). The Gnomonic represents all great circles as straight lines making it suitable for visualizing routes when centered near the majority (Bugayevskiy \& Snyder, 1995; Canters, 2002), though practical use is limited due to unreliable distance measurements (Maling, 1992) and scale distortion increases rapidly from the tangent point so maximum footprint is a hemisphere (Canters, 2002; Gilmartin, 1991). When the focus is a single location, such 
as routes from an airport, the Azimuthal Equidistant shows all great circles from that point as straight lines and can show the entire Earth (Gilmartin, 1991; Kimerling et al., 2012), though any azimuthal projection can be used to focus on particular points or zones of interest (Hsu, 1981; Canters, 2002). Mapping a single aircraft route can use Oblique Mercator with any great circle as the line of zero distortion (Maling, 1992), Azimuthal Equidistant or Gnomonic centered at the route's mid-point (Gilmartin, 1991), or Two-Point Equidistant displaying the spatial relationship between two points and all others (Hsu, 1981; Canters, 2002) such as the distance of a vessel from the voyage start and end points (Snyder \& Voxland, 1989).

The importance of Mercator for maritime navigation is undeniable, as all rhumblines are displayed as straight lines which was the original reason for the projection design (Canters, 2002; Maling, 1992; Robinson, 1991). The Loximuthal displays straight rhumb-lines from a single point and unlike Mercator is true to scale (Snyder, 1993; Snyder \& Voxland, 1989). Skopeliti \& Tsoulos (2013) recommend suitable projections for Arctic marine navigation by analysing infinitesimal scale distortion and visual characteristics, proposing polar aspects of Azimuthal Equidistant or Stereographic for Arctic regions $\left(70-90^{\circ} \mathrm{N}\right)$, and Lambert Conformal Conic or Equidistant Conic for sub-Arctic regions $\left(50-75^{\circ} \mathrm{N}\right)$.

Visualizing ranges of activity from specific locations requires preserving the circular shape of the phenomenon spreading outwards from the source location, e.g. radio / telephone signals or tsunami distance from earthquake epicenter (Muehrcke, 1991). The Azimuthal Equidistant is particularly valuable as distances from the central point to every other location are shown correctly (Canters, 2002). Alternative azimuthal projections can be used for single sources, but the Stereographic is the only projection which displays multiple ranges as circles (Muehrcke, 1991). 
Flow maps display spatial interactions between geographic origin and destination locations, or focus on net or gross flow from a single point (Rae, 2009). Unlike other thematic maps visual portrayal of the route does not require preservation of area (Slocum et al., 2010). Portraying flow patterns at international or global scales is problematic, though the Orthographic is proposed for drawing arrows along great circles (Tobler, 1987), and the Vertical Near-side Perspective is suggested for an example map of migration to the United States from Europe and Asia (Slocum et al., 2010). The Stereographic is especially useful for visualizing flows which spread outward from multiple sources (Canters, 2002). Maps showing movement to/from a single location can use any azimuthal projection with Azimuthal Equidistant particularly suitable as distances to all other locations are correct (Canters, 2002), and for a pair of focus points the previously mentioned Two-Point Equidistant would be suitable.

When mapping certain global properties the previous recommendations for general reference maps may not be appropriate. A map of international time-zones is best displayed using straight meridians (Hsu, 1981), with Miller Cylindrical used in the CIA World Factbook (https://www.cia.gov/library/publications/the-worldfactbook/docs/refmaps.html). Plate Carrée and Equidistant Cylindrical are sometimes referred to as equirectangular as all meridians and parallels are straight and equally spaced (Snyder, 1993), thus also making them suitable for basic outline or index world maps (Snyder \& Voxland, 1989).

Maps are also used for measurements, and "Spatial analysis is in many ways the crux of GIS...” (Longley et al., 2011, p. 352). Numerous works on this subject in the literature are generally based on Euclidean geometry and effectively consider the Earth to be flat (Tobler, 1993), though several references recognize that large footprints 
require accounting for the Earth's curvature (Gatrell, 1983; Longley et al., 2011;

O’Sullivan and Unwin, 2010; Unwin, 1996). Specific projection recommendations are uncommon but generally focus on preserving distances for analysing point patterns (O’Sullivan \& Unwin, 2010), and naturally preferring equal-area projections for area measurements (Chrisman, 2017; Longley et al., 2011). In practice, the national topographic mapping system based on a conformal projection (e.g. Transverse Mercator or Lambert Conformal Conic) is often used (Chrisman, 2017; Chrisman \& Girres, 2016; Maling, 1989). However, little consideration has been given to difficulties which may arise from substituting projected coordinates for Cartesian coordinates in spatial analysis techniques (Tobler, 1964).

GIS tools and techniques do exist which enable the calculation and use of true distances and areas on the ellipsoid, so any selection process must complement these methods and enable users to make intelligent decisions and avoid the elementary mistakes highlighted in the Selection difficulties section.

\section{Development}

\section{List of purposes}

A list of purposes was developed to form the basis of the projection selection procedure (see Table 1). The list is not comprehensive and other purposes (e.g. Climate/Weather) were considered but a lack of detailed research or definitive advice meant that inclusion was impractical at this stage.

---Table 1 near here---

Successful implementation of an automated system first requires conceptual knowledge specification (Jankowski \& Nyerges, 1989). Simultaneously considering both purpose and geographical footprint requirements required development of 
projection selection diagrams for each purpose, specifying a small set of candidate projections for various categories of footprints. Using Snyder's guidelines as a starting point the following footprint categories were defined: World, Hemisphere, North Pole, South Pole, Equatorial, and finally Middle (everything not covered by the other categories). The Middle category is sub-divided by extent type: East-West, NorthSouth, and Equal. Diagram development also considered appropriate data input requirements for that purpose. The diagrams developed for General Reference, Thematic Raster and Navigation Routes (Geodesic) are shown as examples (see Figure 1).

---Figure 1 near here---

Suitable GIS methods were developed to calculate location, size and extent properties of the user input dataset to ensure accurate footprint categorization. Each purpose requires a defined input data type: in some cases a vector feature layer containing either a single polygon encompassing the entire area (such as for General Reference) or a set of individual point, polyline or polygon features (such as polylines for Navigation Routes); and in other cases a raster dataset (such as Thematic Raster).

Determining the most suitable point or line of zero distortion is generally achieved by calculating the geographic center of the footprint. Maling (1992) suggests calculating using plane methods on a suitable map, and various Euclidean geometry techniques have been described by Deakin, Bird, \& Grenfell (2002) and at Geospatial Analysis online (http://www.spatialanalysisonline.com/). Rogerson (2015, p. 686) suggests “...there is no commonly accepted method for its determination" and proposes a new method using an azimuthal equidistant projection from an approximate center to find a new estimation, then carries out a number of iterations so that the projection 
center converges on the geographic center. This technique was therefore chosen due to the appropriate geographic considerations and ease of implementation using GIS.

The footprint category is defined by comparing the input dataset geodesic area to assigned limits, taking account of the input ellipsoid such that appropriate values are used even if an unusual input selection is made such as another celestial body. For single polygon inputs the Hemisphere category is set for areas greater than $1 / 4$ and less than $1 / 2$ the total ellipsoid surface area. Categories for areas smaller than $1 / 4$ are set to Middle, and greater than $1 / 2$ to World. Calculating the area size for input datasets of individual features is more complex. In these cases, a test is made to see if all features fall completely within geodesic buffers from the geographic center as calculated above. The category is set to Middle when the features fall within a buffer at 1/8 of the Equator length, which roughly represents $1 / 4$ of the total area. The Hemisphere category is set when the features fall within a buffer at $1 / 4$ of the Equator, which is roughly $1 / 2$ of the total area, and the World category is set otherwise.

Footprints smaller than the World category are re-assigned to North or South Pole if either maximum latitude is greater than $89^{\circ}$ (accounting for rounding difficulties), or centroid latitude is greater than $70^{\circ}$ (Mekenkamp, 1990; Šavrič, Jenny et al., 2016). Footprints in the Middle category are re-assigned to Equatorial if either the latitude range extends across the Equator, or the absolute value of the centroid latitude is less than $15^{\circ}$ (Šavrič, Jenny et al., 2016).

For the Geospatial Analysis purposes the maximum area for acceptable computations using 2D projected coordinates is rarely addressed. An area under $100 \mathrm{~km}$ $\mathrm{x} 100 \mathrm{~km}$ has been suggested at Geospatial Analysis online (http://www.spatialanalysisonline.com/), whereas the maximum smaller dimension of the U.S. State Plane Coordinate System grid zones is approx. 250km (Mitchell \& 
Simmons, 1945). These zones are designed for land surveys which have a higher accuracy requirement than geospatial analysis, so a buffer limit of $500 \mathrm{~km}$ was subjectively chosen and area inputs larger than this are not possible.

Finally, sub-categorization of the Middle category based on extent properties uses an azimuthal equidistant projection of the input data to calculate a ratio of the differences of the minimum and maximum XY values. Table 2 details the results of trials which established limits at 4/5 (0.8) for areas which extend North-South and 5/4 (1.25) for East-West. The Projection Wizard uses the same ratios based on geographic rather than projected XY coordinates (Šavrič, Jenny et al., 2016).

---Table 2 near here---

For most projections the footprint categorization process also produces the initial projection parameter values. Conic projections utilize the Kavraisky formulas to generate standard parallel values $\left(\emptyset_{1}, \emptyset_{2}\right)$ from maximum and minimum latitudes $\left(\emptyset_{\mathrm{n}}\right.$, $\emptyset_{\mathrm{s}}$ ) (Maling, 1992):

$$
\begin{aligned}
& \emptyset_{1}=\emptyset_{s}+\frac{1}{K}\left(\emptyset_{n}-\emptyset_{s}\right) \\
& \emptyset_{2}=\emptyset_{n}-\frac{1}{K}\left(\emptyset_{n}-\emptyset_{s}\right)
\end{aligned}
$$

The constant $\mathrm{K}$ value is set to 7 for East-West extents (Maling, 1992), and 6 for the Navigation Routes (Geodesic) purpose which is not extent dependent (Bugayevskiy \& Snyder, 1995).

For most combinations of purpose and footprint category there are a number of candidate projection options, so appropriate quantitative and qualitative assessment techniques are required to assist the GIS user in making the final decision. 


\section{Distortion assessment}

Methods for calculating and visualizing projection distortion are primarily based on Tissot's 19th-century infinitesimal scale theorem, described in a number of classic references (Snyder, 1987; Maling, 1992; Bugayevskiy \& Snyder, 1995). Tissot's Indicatrix and isocols (lines of equal distortion) enable map projection comparisons, but potentially give a false impression of the size and distribution of distortion (Mulcahy \& Clarke, 2001; Sun, 2016), fail to represent the cumulative effect of scale distortion over finite distances (Canters, 2002), and require significant additional programming for automated solutions (Bildirici, 2015).

Finite scale methods were therefore preferred to calculate distortion measures in terms of distance, area and shape (Canters, 2002). To calculate finite distance distortion, the Canters (2002) description of the Peters method was chosen to calculate an average distortion value $E_{P}$ for a randomly generated set of $m$ distances, comparing the geodesic $\mathrm{s}_{\mathrm{i}}$ to the corresponding Euclidean $\mathrm{s}_{\mathrm{i}}{ }^{\prime}$ distance:

$$
E_{P}=\frac{1}{m} \sum_{i=1}^{m} \frac{\left|s_{i}-s_{i}{ }^{\prime}\right|}{\left|s_{i}+s_{i}{ }^{\prime}\right|}
$$

A finite area distortion measure was adapted from Peters' distance method (Canters, 2002; Canters, Deknopper, \& De Genst, 2005) to calculate $E_{A}$ using Equation (2) and substituting geodesic area $S_{i}$ and plane area $S_{i}{ }^{\prime}$ for the distances.

To assess finite shape distortion Canters (2002) used an adapted version of the Boyce \& Clark (1964) method which evaluates how a shape such as an urban zone differs from a circle. To overcome a small range of values hampering shape distinction, MacEachren (1985) recommended a symmetric difference method which similarly compares an unknown shape to one easily described such as a circle (Lee \& Sallee, 1970). This latter method was chosen to calculate an index $r$ using geometric 
intersection and union areas for a shape $K$ and circle $L$, which can be readily implemented in GIS by comparing the shape of a projected geodesic buffer $(K)$ to a circular buffer created on the projection using the same distance value $(L)$ :

$$
r=1-\left[\frac{\operatorname{area}(K \cap L)}{\operatorname{area}(K \cup L)}\right]
$$

Sample point locations are required for distortion assessment. A regular approach using equal-angle grids is straightforward, but fundamental geographic problems are encountered especially due to meridian convergence (Baselga, 2018). Random sampling has practical advantages (Kimerling, Overton, \& White, 1995), but a simple method employing Fibonacci lattices based on the so-called golden ratio $\Phi$ was chosen to generate an evenly distributed set of points (Baselga, 2018; Gonzalez, 2010). Let $N$ be any natural number and the total number of points $P=2 N+1$. For integer $i$ in the range $-\mathrm{N},(-\mathrm{N}+1), \ldots, 0, \ldots,(\mathrm{N}-1), \mathrm{N}$ :

$$
\begin{aligned}
& \Phi=1+\frac{1}{\Phi}=\frac{(1+\sqrt{5})}{2} \\
& \varphi_{i}=\arcsin \frac{2 i}{P} \times \frac{180^{\circ}}{\pi} \\
& \lambda_{i}=\bmod (i, \Phi) \times \frac{360^{\circ}}{\Phi}
\end{aligned}
$$

$N$ is subjectively assigned based on the size of the footprint to avoid excessive runtimes, then assessment points are selected that are within polygon inputs or within a distance of point $(1,000 \mathrm{Km})$ or line $(100 \mathrm{Km})$ features. For distance distortion, a line dataset is created by randomly selecting start and end locations from the assessment point dataset, employing a 5:1 distance to point ratio similar to Canters (2002). For area and shape distortion the assessment points are used as the center point for buffers using a randomly generated distance value up to a maximum of $1,000 \mathrm{~km}$.

Raster datasets provide unique challenges as re-projection requires re-sampling 
to a new regular cell framework and inevitably leads to data loss from the original dataset (Kimerling, 2002; Mulcahy, 2000; Steinwand et al., 1995; Usery \& Seong, 2001). Steinwand et al. (1995) employed 10km-square checkerboard raster data patterns to visualize re-projection and calculate simple metrics. Mulcahy (2000) used a $1 \mathrm{~km}$ raster grid of unique values to develop Pixel Loss and Pixel Duplication measures, but an initial transformation using the Plate Carrée projection adversely impacts the results due to an enlargement of the number of pixels, increasing with latitude, caused by the incompatibility between the original (equal-angle) and projected (metric) raster frameworks. Kimerling (2002) employed similar techniques to create a Data Loss and Duplication Map (DLDM) displaying latitude/longitude errors when projecting raster data stored using Equidistant Cylindrical (Plate Carrée), carefully determining pixel density and scale ratio values so that original and projected grids are as compatible as possible. Separate methods to effectively communicate differences in vector and raster data transformations are desirable (Mulcahy \& Clarke, 2001), but the raster methods described do not adequately quantify projection distortion and are not easily implemented in a GIS projection selection process. Therefore, for raster inputs the finite distortion measures described are used, giving an indication of deformation rather than specific data loss evaluation statistics.

For all three finite measures, zero indicates no distortion increasing to a maximum value of 1 . A simple index can be calculated by adding together the measures to indicate the candidate with the least distortion, though combining different kinds of projection distortion is complicated by the different units involved (Canters, 2002; Laskowski, 1997). Weighting the relative importance of each measure by setting zero when the particular distortion is not relevant to the purpose can be applied (see Table 3). Bugayevskiy \& Snyder (1995) explained this approach for infinitesimal scale theory 
and also highlighted that additional research was required to appropriately determine the significance of measures for particular purposes. Canters et al. (2005) suggest that an orthophanic ('right appearing') projection would have the least combined area and shape distortion, so this weighting was chosen for many purposes unless there was a straightforward reason to select otherwise. Preservation of area is crucial for the two Thematic purposes and Geospatial Analysis (Area), so these selection diagrams are purely based on equal-area projections and the distance and shape measures are weighted zero. Similarly for Geospatial Analysis (Distance) and Ranges of Activity purposes the key preservation characteristic is distance so for these the area and shape measures are weighted zero.

---Table 3 near here---

\section{Parameter optimization}

Testing different projections and modifying parameters to find the optimal solution is essential (Hsu, 1981), though careful consideration is required as parameters which minimize a mean distortion statistic may cause an undesirable greater overall range of scale errors (Canters, 2002). Many authors have employed quantitative distortion methods to create minimum-error projections using mathematical techniques such as least-squares to minimize infinitesimal scale distortion errors throughout the map (Bugayevskiy \& Snyder, 1995; Canters, 2002; Maling, 1992). However, the theory is not well known to cartographers (Maling, 1992), and complex mathematics are required to create world map projections which are essentially academic rather than practically useful as projections ideally need to be familiar and understandable to map users (Snyder, 1994). 
Adding parameter optimization techniques to the automated selection tool to reduce the combined distortion index is feasible for a couple of projection types included on the conceptual diagrams. Conic projections use a subjective K constant value to calculate standard parallels (Equations 1a and $1 \mathrm{~b}$ ), so modifying $\mathrm{K}$ values between 3 and 7 have been proposed for different footprints (Maling, 1992). The K value with the least combined distortion index is therefore used to optimize choice of standard parallels. Some projections, i.e. Transverse Mercator and Stereographic, set a scale factor parameter for the point or line of zero distortion to minimize distortion throughout the footprint. The minimum scale factor value found in traditional grid systems is 0.9996 for Universal Transverse Mercator (UTM) grid zones due to their global scope (Chrisman and Girres, 2016), so a regular set of values between 0.9996 and 1 (step 0.0001) can be used for further assessments.

Many other projection types are defined using a single latitude, longitude or latitude/longitude pair, and, as the centroid calculation provides a location that best approximates the geographic center, no further optimization is necessary. Similarly, Hotine Oblique Mercator and Two-Point Equidistant are only used where the end points of a single line or two individual features define the projection parameters directly. For other projections with potentially modifiable parameters the optimum result is primarily aesthetic rather than distortion reduction. For Equidistant Cylindrical the $45^{\circ}$ standard parallel was chosen for World Index, providing an alternative to Plate Carrée which is effectively the same projection using the Equator as standard parallel. The WinkelTripel standard parallel is set to $40^{\circ}$ as per the Times Atlas version (Snyder, 1993). Vertical Near-Side Perspective produces different graphical views depending on the height value selected (Slocum et al., 2010), so to make best use of this option the user would need to test a number of options to determine the optimum height for their 
requirements. For these projections, user notes have been added to the results to explain the potential to manually modify the parameters to achieve the ideal visual results.

\section{Tool development}

The existing automated selection tools are generally bespoke standalone systems, but GIS software can handle functions associated with projection choice so specialist solutions are unnecessary. Using ESRI ArcGIS software, a Python Add-in for ArcGIS Desktop toolset was developed using the Python scripting language and ArcPy site package. The tool must enable modification of the ArcGIS map document data frame coordinate system property, and this is achieved in ArcPy using spatial reference objects. Parameters are projection dependent but common combinations were used to create a categorization for efficient object creation. The ArcGIS project-on-the-fly capability was preferred for visualizing candidate projection outputs, primarily to avoid re-sampling and data loss using raster data when re-projecting input layers.

Once the ArcGIS Add-in has been installed and Automated Projection Selection toolbar enabled, the user adds their Project Name text, selects the Purpose, and chooses an appropriate Input Dataset from their project which defines the footprint, before clicking the Run Tool button (see Figure 2).

---Figure 2 near here---

A results text file is created which lists input characteristics and distortion assessment results for all candidate projections. The Projected Coord System drop-down list is now enabled with candidates in ascending order of combined distortion index. Clicking the Apply button modifies the data frame coordinate system to the chosen candidate, and the user is advised to add a graticule using Layout View to optimally compare different options. A full quantitative and qualitative review is now possible using the results file and graphical output. 


\section{Results}

This section includes a few examples to display the results and highlight the value of the functions included in the automated selection tool. See Appendix 1 for the output text files for each of the examples.

\section{General Reference map of the Conterminous United States}

The conterminous United States is assessed in the East-West extent category and results in two candidates for the initial constant value $K=7$ : Equidistant Conic (Combined Index $=0.01194)$; Lambert Conformal Conic (0.02375). When optimizing K values for the Equidistant Conic the setting $\mathrm{K}=3$ is ranked first (0.00745) (see Appendix 1). The final result (Figure 3a) has standard parallels $33^{\circ} 15^{\prime} \mathrm{N}$ and $41^{\circ} 15^{\prime} \mathrm{N}$ with Central Meridian $98^{\circ} 48^{\prime} 37^{\prime \prime} \mathrm{W}$, and is visually very similar to the Albers Equal-Area Conic (Figure 3b) with standard parallels $29^{\circ} 30^{\prime} \mathrm{N}$ and $45^{\circ} 30^{\prime} \mathrm{N}$, and Central Meridian $96^{\circ} \mathrm{W}$, which is routinely used for maps of the United States (Snyder, 1993). The Add-in tool is not designed to calculate distortion measures for input projection definitions, but using the same functions for the Albers Equal-Area Conic projection a combined index of 0.00850 is calculated for comparison purposes.

---Figure 3 near here---

\section{Thematic Raster map of Australia}

A case study based on the National Dynamic Land Cover Dataset of Australia (https://ecat.ga.gov.au/geonetwork/srv/eng/catalog.search\#/metadata/83868), results in three candidates for the Middle category. All candidates are equal-area and have a combined index very close to zero: Sinusoidal $\left(28 \times 10^{-10}\right)$; Lambert Azimuthal EqualArea $\left(36 \times 10^{-10}\right)$; Bonne $\left(42 \times 10^{-10}\right)$ (see Appendix 1). For equal-area cases, the ranking of candidates is effectively arbitrary, probably governed by round-off errors and 
other minor differences in calculations. Final selection can be for aesthetic reasons with the former provided as an example (Figure 4a), and a comparison can be made with the Lambert Conformal Conic (Standard Parallels $18^{\circ} \mathrm{S}, 36^{\circ} \mathrm{S}$, Central Meridian $134^{\circ} \mathrm{E}$ ) used by Geoscience Australia for a map of land cover data published in 2011 (https://ecat.ga.gov.au/geonetwork/srv/eng/catalog.search\#/metadata/70138) (Figure 4b). This projection is not mentioned in the literature for raster purposes, and using the distortion measures a combined index of 0.01178 is calculated for comparison. The map has sensibly been produced without projecting and re-sampling the data, similar to the developed tool which utilizes the ArcGIS project-on-the-fly capability.

---Figure 4 near here---

A comparison with the Projection Wizard can also be made in this case by selecting the equal-area property resulting in a Lambert Azimuthal Equal-Area recommendation, noting this is the only candidate and has not been suggested specifically for raster purposes (Figure 5). Using the distortion measures a combined index of $36 \times 10^{-10}$ is calculated for comparison.

---Figure 5 near here---

\section{Navigation Routes (Geodesic) from Miami to Tokyo}

The example route from Miami to Tokyo as used by Gilmartin (1991) results in four candidates for the single line input option of this purpose: Hotine Oblique Mercator (0.00210); Azimuthal Equidistant (0.07270); Two-Point Equidistant (0.18361); Gnomonic (0.55317) (see Appendix 1). The former provides the least amount of distortion and a clear visual display of the shortest route using a straight line (Figure 6a). This is compared with the normal aspect of the Mercator projection to show why the latter is not a good choice for visualizing geodesic routes (Figure 6b), and using the distortion measures results in a large combined index of 1.00789 . 
---Figure 6 near here---

\section{Conclusion}

Map projection selection is complex and difficult to comprehend for many cartographers and GIS users. The aim of this project was to create an accessible automated selection tool enabling appropriate decision-making and aiding general improvements to map projection knowledge and understanding. The finished solution is broadly successful in meeting this aim, allowing candidate projections to be evaluated quantitatively, using a textual output of results, and qualitatively, by enabling a graphical view for each option using the GIS data frame.

Developing an automated projection selection tool has demonstrated the possibilities of creating a selection scheme based on the two essential criteria, i.e. purpose (rather than distortion property as a surrogate) and geographic footprint characteristics. Lack of a complete knowledge of the relationship between purpose and distortion properties is detrimental to selection strategies (Canters, 2002), so the projection selection diagrams designed for this project are the first known attempt to conceptualize this association. The Purpose selection from a drop-down list is straightforward, and whilst the list is not comprehensive additional purposes could be included when sufficient recommendations in the literature support creation of additional selection diagrams.

The most significant benefits are realized by incorporating the tool within GIS and directly using the functions provided by the ESRI ArcPy site package for ArcGIS to determine input dataset geographic area characteristics and perform distortion assessments. Integrating the solution with GIS enables new techniques to be developed to treat the area of interest as a true geographic object, e.g. using a centroid calculation 
method based on iteratively applying an azimuthal equidistant projection similar to Rogerson (2015).

A new distortion assessment procedure was created using finite methods to account for the cumulative distortion of distance, area and shape properties over large areas, resulting in a combined index allowing comparison between different options and assisting the user in making their final selection. A further advantage provided by the purpose selection is that different types of distortion can be weighted depending on relevance to that purpose, an approach originally recommended by Bugayevskiy \& Snyder (1995). Resources are saved by avoiding running un-necessary distortion functions, especially relevant for the intensive shape process.

It is essential that the user can undertake both quantitative analysis of their options using the distortion assessment, and also qualitative analysis by reviewing the graphical output that results from applying each of the candidates. The tool provides a simple drop-down selection and button click to achieve this which is more straightforward than the normal method using the data frame properties dialog box. Projection definition (.prj) files are generated for each candidate, so the user can also easily import these to ArcGIS using the standard procedure and modify parameters as necessary to consider additional options.

There are several potential avenues for future development of the toolset. The selection diagrams are limited by the lack of studies into projections which are appropriate for different purposes, so it is hoped that interest in the tool could help focus research in this direction. More practically, specific projections could be added if they became available in ArcGIS, e.g. the interrupted Mollweide recommended for raster data (Steinwand et al., 1995), and purposes with extent-based selections could employ the Hotine Oblique Mercator cylindrical projection for extents not well represented by 
the cardinal directions. Modifying the tool to employ the Orthographic as the default display rather than Plate Carrée would likely further aid projection understanding and promote effective GIS use (Goodchild, 1992).

The original intent of incorporating distortion distribution visualization has not been achieved due to the use of finite methods which are designed to present a single index to consider the cumulative effect of projection distortion over large areas. Infinitesimal methods evaluate distortion measures at a point, so techniques such as Tissot's Indicatrix and isocols would meet this need but these require complicated formulas for each projection to be coded. The tool could potentially be modified to accept user input distortion weights, enabling non-binary value choices based on the user needs or future research into appropriate values, and employ distortion assessment techniques avoiding random generation of distances and buffer sizes enabling the results to be repeatable for the same purpose and footprint. Allowing other criteria to enter in the composite index would be of particular importance to resolve the issue that equalarea projections all score effectively zero on the area criterion.

Further research for geospatial analysis purposes is required to fully consider projection selection impact for methods based on Euclidean space, and also to determine appropriate size limits for zones of interest using these techniques. It is unclear how users should proceed for large areas, with possible alternatives being techniques to correct scale deformations or avoiding projections altogether (Chrisman, 2017). Several recent studies have started to recognize and address these considerations, including appropriate interpretation of projection-based analysis (Battersby, Strebe, \& Finn, 2017), inappropriate use of equal-angular 'grids' (Florinsky, 2017), and using spherical methods to improve Voronoi tessellations (Kastrisios \& Tsoulos, 2018) and cartograms (Li \& Aryana, 2018). Developing a robust method for assessing raster data 
distortion would be extremely beneficial, as would expanding the tool availability using similar functionality based on open-source Python methods for other GIS systems such as QGIS.

In general, improvements have been made when compared with existing solutions for the same problem, especially in providing capabilities that are not available within existing GIS software packages where projection decisions are being made. The solution positively impacts GIS users by simplifying the selection process, and direct and flexible interaction with projections together with studying associated results and notes could lead to broader understanding of map projections, selection criteria and GIS handling of geographic data. The tool has the potential to significantly enhance user confidence and experience and ultimately lead to better maps and analysis through more effective use of GIS.

The Automated Projection Selection Python Add-in for ArcGIS is available at: https://github.com/pcgosling/ArcGIS-ProjectionSelection

\section{Acknowledgements}

Datasets used to create the examples in the Results section include: Natural Earth data which is freely available from http://www.naturalearthdata.com/ without copyright restrictions; and Dynamic Land Cover Dataset of Australia V2.1 data which is supplied by Geoscience Australia using the Creative Commons 4.0 Attribution International licence.

\section{References}

Anderson, K.C., \& Leinhardt, G. (2002). Maps as Representations: Expert Novice Comparison of Projection Understanding. Cognition and Instruction, 20(3), 283-321. doi:10.1207/S1532690XCI2003_1 
Baselga, S. (2018). Fibonacci lattices for the evaluation and optimization of map projections. Computers \& Geosciences, 117, 1-8. doi:10.1016/j.cageo.2018.04.012

Battersby, S.E. (2009). The effects of global-scale map projection knowledge on perceived land area. Cartographica, 44(1), 33-44. doi:10.3138/carto.44.1.33

Battersby, S.E., Strebe, D., \& Finn, M.P. (2017). Shapes on a plane: Evaluating the impact of projection distortion on spatial binning. Cartography and Geographic Information Science, 44(5), 410-421. doi:10.1080/15230406.2016.1180263

Bildirici, I.O. (2015). Quasi indicatrix approach for distortion visualization and analysis for map projections. International Journal of Geographical Information Science, 29(12), 2295-2309. doi:10.1080/13658816.2015.1074236

Boyce, R.R., \& Clark, W.A.V. (1964). The concept of shape in geography. Geographical Review, 54(4), 561-572. doi:10.2307/212982

Brainerd, J., \& Pang, A. (2001). Interactive Map Projections and Distortion. Computers \& Geosciences, 27(3), 299-314. doi:10.1016/S0098-3004(00)00108-4

Bugayevskiy, L.M., \& Snyder, J.P. (1995). Map Projections: A Reference Manual. London: Taylor \& Francis. doi:10.1201/b16431

Canters, F. (1989). New Projections for World Maps: A Quantitative-Perceptive Approach. Cartographica, 26(2), 53-71. doi:10.3138/6212-46V4-655U-766K

Canters, F. (1991). Map Projection in a GIS Environment. In K. Rybaczuk, \& M. Blakemore (Eds.), Mapping the Nations: Proceedings of the 15th Conference of the International Cartographic Association Volume 2, Bournemouth, UK (pp.595-604). London: International Cartographic Association.

Canters, F. (2002). Small-Scale Map Projection Design. London: Taylor \& Francis. doi:10.1201/b12656

Canters, F., \& Decleir, H. (1989). The World In Perspective: A Directory Of World Map Projections. Chichester: J. Wiley \& Sons Ltd.

Canters, F., Deknopper, R., \& De Genst, W. (2005, July). A New Approach for Designing Orthophanic World Maps. Paper presented at the 22nd International Cartographic Conference, A Coruña, Spain.

Carbon, C. (2010). The Earth is flat when personally significant experiences with the sphericity of the Earth are absent. Cognition, 116(1), 130-135. doi:10.1016/j.cognition.2010.03.009 
Chrisman, N.R. (2017). Calculating on a round planet. International Journal of Geographical Information Science, 31(4), 637-657. doi:10.1080/13658816.2016.1215466

Chrisman, N., \& Girres, J.F. (2016). First do no harm: eliminating systematic error in analytical results of GIS applications. In W. Shi, B. Wu, \& A. Stein (Eds.), Uncertainty modelling and quality control for spatial data (Chapter 3, pp. 2744). Boca Raton, FL: CRC Press. doi:10.1201/b19160

De Genst, W., \& Canters, F. (1996). Development and Implementation of a Procedure for Automated Map Projection Selection. Cartography and Geographic Information Science, 23(3), 145-171. doi:10.1559/152304096782438864

Deakin, R.E., Bird, S.C., \& Grenfell, R.I. (2002). The Centroid? Where would you like it to be? Cartography, 31(2), 153-167. doi:10.1080/00690805.2002.9714213

Dent, B.D. (1999). Cartography: Thematic Map Design (5th ed.). Boston, MA: McGraw-Hill.

Downs, R.M., \& Liben, L.S. (1991). The development of expertise in geography: A cognitive-developmental approach to geographic education. Annals of the Association of American Geographers, 81(2), 304-327. doi:10.1111/j.14678306.1991.tb01692.x

Egenhofer, M. J., \& Mark, D. M. (1995). Naive Geography. In A. U. Frank, \& W. Kuhn, (Eds.), Spatial Information Theory: A Theoretical Basis for GIS. Lecture Notes in Computer Sciences No. 988 (pp. 1-15). Berlin: Springer-Verlag. doi:10.1007/3-540-60392-1_1

Eldrandaly, K.A. (2006). A COM-based expert system for selecting the suitable map projection in ArcGIS. Expert Systems with Application, 31, 94-100. doi:10.1016/j.eswa.2005.09.008

Finn, M.P., Usery, E.L., Posch, S.T., \& Seong, J.C. (2004). A Decision Support System for Map Projections of Small Scale Data (Scientific Investigations Report 20045297). Reston, VA: United States Geological Survey (USGS). doi:10.3133/sir20045297

Florinsky, I.V. (2017). Spheroidal equal angular DEMs: The specificity of morphometric treatment. Transactions in GIS, 21(6), 1115-1129. doi:10.1111/tgis.12269

Gatrell, A. C. (1983). Distance and Space: A Geographical Perspective. Oxford: Oxford University Press. doi:10.2307/143882 
Gilmartin, P.P. (1991). Showing the Shortest Routes - Great Circles. In A.H. Robinson, \& J.P. Snyder (Eds.) Matching the Map Projection to the Need (pp.18-19). Bethesda, MD: American Congress on Surveying and Mapping.

Goldberg, D.M., \& Gott, J.R. (2007). Flexion and Skewness in Map Projections of the Earth. Cartographica, 42(4), 297-318. doi:10.3138/carto.42.4.297

Gonzalez, A. (2010). Measurement of Areas on a Sphere Using Fibonacci and LatitudeLongitude Lattices. Mathematical Geosciences, 42(1), 49-64. doi:10.1007/s11004-009-9257-x

Goodchild, M.F. (1992). Geographical information science. International Journal of Geographical Information Systems, 6(1), 31-45. doi:10.1080/02693799208901893

Goodchild, M.F. (2018). Reimagining the history of GIS. Annals of GIS, 24(1), 1-8. doi:10.1080/19475683.2018.1424737

Hruby, F., \& Riedl, A. (2018). 2000 Years of 'globes vs. maps' - lessons (to be) learned. International Journal of Cartography, 4(2), 186-200. doi:10.1080/23729333.2017.1422097

Hsu, M-L. (1981). The Role of Projections in Modern Map Design. Cartographica, 18(2), 151-186. doi:10.3138/9821-M648-7189-0088

Hunter, G.J., \& Reinke, K.J. (2000, July). Adapting Spatial Databases to Reduce Information Misuse Through Illogical Operations. In G.P.M. Heuvelink, \& M.J.P.M. Lemmens (Eds.), Accuracy 2000: Proceedings of 4th International Symposium on Spatial Accuracy Assessment in Natural Resources and Environmental Sciences, Amsterdam, Netherlands (pp. 313-319). Delft: Delft University Press.

Ivanov, A.G., \& Zagrebin, G.I. (2011, July). Working out the methods of realisation of elements of the mathematical basis of maps. In A. Raus (Ed.), Proceedings of the 25th International Cartographic Conference, Paris, France.

Jankowski, P., \& Nyerges, T.L. (1989). Design Considerations for MaPKBS-Map Projection Knowledge-Based System. American Cartographer, 16(2), 85-95. doi: $10.1559 / 152304089783875514$

Kastrisios, C., \& Tsoulos, L. (2018). Voronoi tessellation on the ellipsoidal earth for vector data. International Journal of Geographical Information Science, 32(8), 1541-1557. doi:10.1080/13658816.2018.1434890 
Kerkovits, K., \& Gede, M. (2017). Web-based Decision Support System for Choosing the Appropriate Map Projection. Poster presented at the 28th International Cartographic Conference, Washington DC, USA.

Kessler, F.C. (2000). A Visual Basic Algorithm for the Winkel Tripel Projection. Cartography and Geographic Information Science, 27(2) 177-183. doi:10.1559/152304000783547939

Kessler, F.C. (2018). Map Projection Education in Cartography Textbooks: A Content Analysis. Cartographic Perspectives, 90, 6-30. doi:10.14714/CP90.1449

Kimerling, A.J. (2002). Predicting Data Loss and Duplication when Resampling from Equal-Angle Grids. Cartography and Geographic Information Science, 29(2), 111-126. doi:10.1559/152304002782053297

Kimerling, A.J., Buckley, A.R., Muehrcke, P.C., \& Muehrcke, J.O. (2012). Map Use: Reading, Analysis, and Interpretation (7th ed.). Redlands, CA: ESRI Press.

Kimerling, A.J., Overton, S.W., \& White, D. (1995). Statistical Comparison of Map Projection Distortion within Irregular Areas. Cartography and Geographic Information Science, 22(3) 205-221. doi:10.1559/152304095782540348

Laskowski, P. (1997). Distortion-Spectrum Fundamentals: A New Tool for Analyzing and Visualizing Map Distortions [Monograph 50]. Cartographica, 34(3), 3-18. doi:10.3138/Y51X-1590-PV21-136G

Lee, D.R., \& Sallee, G.T. (1970). A Method of Measuring Shape. Geographical Review, 60(4), 555-563. doi:10.2307/213774

Li, Z., \& Aryana, S. (2018). Diffusion-based cartogram on spheres. Cartography and Geographic Information Science, 45(5), 464-475. doi:10.1080/15230406.2017.1408033

Longley, P.A., Goodchild, M.F., Maguire, D.J., \& Rhind, D.W. (2011). Geographic Information Systems \& Science (3rd ed.). Hoboken, NJ: John Wiley \& Sons, Inc.

MacEachren, A.M. (1985). Compactness of Geographic Shape: Comparison and Evaluation of Measures. Geografiska Annaler Series B, Human Geography, 67(1), 53-67. doi:10.1080/04353684.1985.11879515

Maling, D.H. (1989). Measurements from Maps: Principles and Methods of Cartometry. Oxford: Pergamon Press.

Maling, D.H. (1992). Coordinate Systems and Map Projections (2nd ed.). Oxford: Pergamon Press. 
Mekenkamp, P.G.M. (1990, April). The need for projection on parameter in a GIS environment. In J.J. Harts, H.F.L. Ottens, \& H.J. Scholtes (Eds.), EGIS '90: Proceedings, First European Conference on Geographical Information Systems, Amsterdam, Netherlands (pp.762-769). Utrecht: EGIS Foundation.

Mekenkamp, P.G.M. (2005, July). Using Map Projections without Changing the World: Projection Accuracy Analyses. Paper presented at the 22nd International Cartographic Conference, A Coruña, Spain.

Mitchell, H.C., \& Simmons, H.G. (1945). The State Coordinate Systems (A Manual for Surveyors) (Coast and Geodetic Survey Special Publication No.235). Washington, DC: United States Government Printing Office.

Muehrcke, P.C. (1991). Showing Ranges and Rings of Activity. In A.H. Robinson, \& J.P. Snyder (Eds.) Matching the Map Projection to the Need (pp.24-25). Bethesda, MD: American Congress on Surveying and Mapping.

Mulcahy, K.A. (2000). Two New Metrics for Evaluating Pixel-Based Change in Data Sets of Global Extent due to Projection Transformation. Cartographica, 37(2), 1-12. doi:10.3138/C157-258R-2202-5835

Mulcahy, K.A., \& Clarke, K.C. (2001). Symbolization of Map Projection Distortion: A Review. Cartography and Geographic Information Science, 28(3) 167-181. doi:10.1559/152304001782153044

Nyerges, T.L., \& Jankowski, P. (1989). A Knowledge Base for Map Projection Selection. American Cartographer, 16(1), 29-38. doi:10.1559/152304089783875622

O’Sullivan, D., \& Unwin, D.J. (2010) Geographic Information Analysis (2nd ed.). Hoboken, NJ: John Wiley \& Sons, Inc.

Olson, J.M. (2006). Map Projections and the Visual Detective: How to Tell if a Map is Equal-Area, Conformal, or Neither. The Journal of Geography, 105(1), 13-32. doi:10.1080/00221340608978655

Rae, A. (2009). From spatial interaction data to spatial interaction information? Geovisualisation and spatial structures of migration from the 2001 UK census. Computers, Environment and Urban Systems, 33(3), 161-178. doi:10.1016/j.compenvurbsys.2009.01.007

Robinson, A.H. (1974). A New Map Projection: Its Development and Characteristics. In G.M. Kirschbaum \& K-H Meine (Eds.), International Yearbook of Cartography Volume XIV (pp.145-155). London: George Philip \& Son Limited. 
Robinson, A.H. (1988). Choosing a World Map: Attributes, Distortions, Classes, Aspects. Falls Church, VA: American Congress on Survey and Mapping.

Robinson, A.H. (1991). Straightening a Rhumb. In A.H. Robinson, \& J.P. Snyder (Eds.) Matching the Map Projection to the Need (pp.20-21). Bethesda, MD: American Congress on Surveying and Mapping.

Rogerson, P.A. (2015). A New Method for Finding Geographic Centers, with Application to U.S. States. The Professional Geographer, 67(4), 686-694. doi:10.1080/00330124.2015.1062707

Šavrič, B., Jenny, B., Patterson, T., Petrovic, D., \& Hurni, L. (2011). A Polynomial Equation for the Natural Earth Projection. Cartography and Geographic Information Science, 38(4), 363-372. doi:10.1559/15230406384363

Šavrič, B., Jenny, B., \& Jenny, H. (2016). Projection Wizard - An Online Map Projection Selection Tool. Cartographic Journal, 53(2), 177-185. doi:10.1080/00087041.2015.1131938

Šavrič, B., Patterson, T., \& Jenny, B. (2016). The Natural Earth II World Map Projection. International Journal of Cartography, 1(2), 123-133. doi:10.1080/23729333.2015.1093312

Seong, J.C., Mulcahy, K.A., \& Usery, E.L. (2002). The Sinusoidal Projection: A New Importance in Relation to Global Image Data. Professional Geographer, 54(2), 218-225. doi:10.1111/0033-0124.00327

Seong, J.C., \& Usery, E.L. (2003). Assessing Raster Representation Accuracy Using a Scale Factor Model. Photogrammetric Engineering \& Remote Sensing, 67(10), $1185-1191$.

Skopeliti, A., \& Tsoulos, L. (2013). Choosing a Suitable Projection for Navigation in the Arctic. Marine Geodesy, 36(2), 234-259. doi:10.1080/01490419.2013.781087

Slocum, T.A., McMaster, R.B., Kessler, F.C., \& Howard, H.H. (2010). Thematic Cartography and Geovisualization (3rd ed.). Upper Saddle River, NJ: Pearson Education Inc.

Smith, D.G., \& Snyder, J.P. (1988). Expert Map Projection Selection System. In US Geological Survey Yearbook, Fiscal Year 1988, 14-15.

Snyder, J.P. (1987). Map Projections - A Working Manual (U.S. Geological Survey Professional Paper 1395). Washington, DC: United States Government Printing Office. 
Snyder, J.P. (1993). Flattening the Earth: Two Thousand Years of Map Projections. Chicago, IL: University of Chicago Press.

Snyder, J.P. (1994). How practical are minimum-error map projections? Cartographic Perspectives, 17(4), 3-9. doi:10.14714/CP17.942

Snyder, J.P., \& Voxland, P.M. (1989). An Album of Map Projections (U.S. Geological Survey Professional Paper 1453). Washington, DC: United States Government Printing Office.

Steinwand, D.R. (1994). Mapping raster imagery to the Interrupted Goode Homolosine Projection. International Journal of Remote Sensing, 15(17), 3463-3471. doi:10.1080/01431169408954340

Steinwand, D.R., Hutchinson, J.A., \& Snyder, J.P. (1995). Map projections for global and continental data sets and an analysis of pixel distortion caused by reprojection. Photogrammetric Engineering \& Remote Sensing, 61(12), 14871497.

Sun, S. (2016). Symbolize map distortion with inscribed circles in polygons.

International Journal of Cartography, 2(2), 166-185. doi:10.1080/23729333.2016.1179863

The Times (2014). The Times Comprehensive Atlas of the World (14th ed.). Glasgow: Times Books.

Tobler, W.R. (1962). A Classification of Map Projections. Annals of the Association of American Geographers, 52(2), 167-175.

Tobler, W.R. (1964). Geographical coordinate computations Part II: Finite map projection distortions (Technical Report No. 3, ONR Task no. 389-137). Ann Arbor, Michigan, USA: University of Michigan Department of Geography.

Tobler, W.R. (1987). Experiments in migration mapping by computer. American Cartographer, 14(2), 155-163. doi:10.1559/152304087783875273

Tobler, W.R. (1993). Three Presentations on Geographical Analysis and Modeling: Non- Isotropic Geographic Modeling; Speculations on the Geometry of Geography; and Global Spatial Analysis (National Center for Geographic Information and Analysis Technical Report 93-1). Santa Barbara, CA: University of California.

Tyner, J.A. (2010). Principles of Map Design. New York, NY: The Guilford Press. Unwin, D.J. (1996). GIS, spatial analysis and spatial statistics. Progress in Human Geography, 20(2), 540-551. doi:10.1177/030913259602000408 
Usery, E.L., \& Seong, J.C. (2000, August). A comparison of equal-area map projections for regional and global raster data. Paper presented at the 29th International Geographic Congress, Seoul, Korea.

Usery, E.L., \& Seong, J.C. (2001). All Equal-Area Map Projections Are Created Equal, But Some Are More Equal Than Others. Cartography and Geographic Information Science, 28(3), 183-193. doi:10.1559/152304001782153053

White, D. (2006). Display of Pixel Loss and Replication in Reprojecting Raster Data from The Sinusoidal Projection. GeoCarto International, 21(2), 19-22. doi:10.1080/10106040608542379

Zhao, H., Zhu, H., Li, L., \& Xing, Y. (2007). COM-based expert system for map projection selection. In M. Li, \& J. Wang (Eds.), Geoinformatics 2007: Cartographic Theory and Models, Proceedings of Society of Photo-Optical Instrumentation Engineers (SPIE). Bellingham, WA: SPIE. doi:10.1117/12.759722 


\section{Appendix 1. Output text files for Results section}

\section{General Reference map of the Conterminous United States}

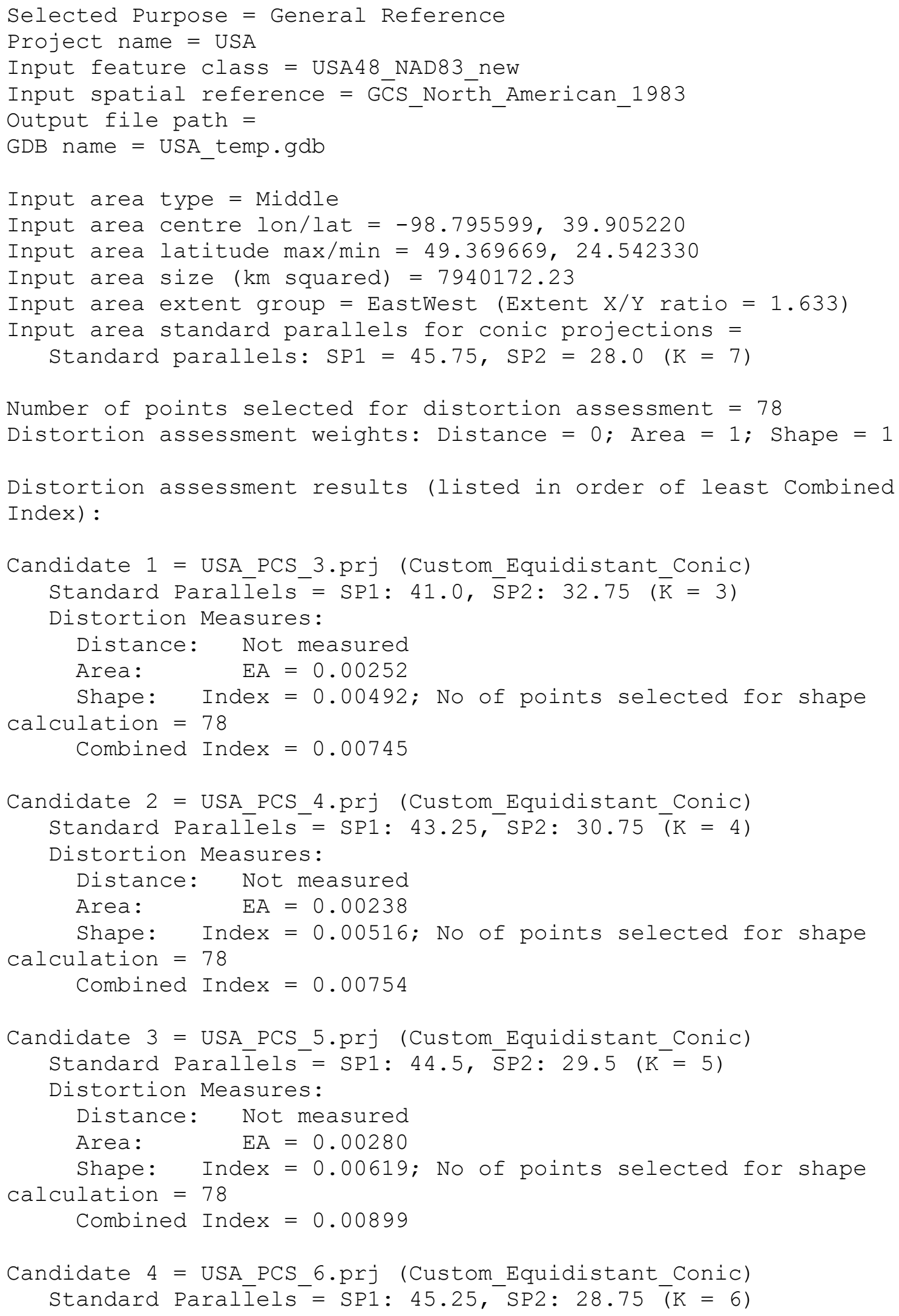


Distortion Measures:

Distance: Not measured

Area: $\quad \mathrm{EA}=0.00324$

Shape: Index $=0.00715$; No of points selected for shape calculation $=78$

Combined Index $=0.01039$

Candidate 5 = USA_PCS_1.prj (Custom_Equidistant_Conic)

Standard parallels: $\mathrm{SP} 1=45.75, \mathrm{SP} 2=28.0(\mathrm{~K}=7)$

Distortion Measures:

Distance: Not measured

Area: $\quad \mathrm{EA}=0.00372$

Shape: Index $=0.00821$; No of points selected for shape calculation $=78$

Combined Index $=0.01194$

Candidate 6 = USA_PCS_2.prj (Custom_Lambert_Conformal_Conic)

Standard paraliels $\overline{\mathrm{SP}} 1=45.75, \overline{\mathrm{SP}} 2=2 \overline{8} .0 \quad(\mathrm{~K}=7 \overline{)}$

Distortion Measures:

Distance: Not measured

Area: $\quad E A=0.00739$

Shape: Index $=0.01636$; No of points selected for shape calculation $=78$

Combined Index $=0.02375$

Projection notes:

- Conic (Albers, Lambert Conformal, Equidistant) - if distortion assessment is employed and one of these projections is the number one rank for the initial standard parallel and $\mathrm{K}$ value settings, then all remaining $K$ values between 3 and 7 will be used to create and assess additional standard parallel options.

- Areas smaller than World or Hemisphere size - the user is advised that in many situations an additional sensible choice can be the reference system used by the local or national mapping agency, or in global use such as the UTM system. This is especially true if certain datasets to be used in the project are already referenced to that system. Note that these systems mostly use conformal map projections such as Transverse Mercator and Lambert Conformal Conic.

\section{Thematic Raster map of Australia}

Selected Purpose = Thematic Raster

Project name = Australia

Input feature class $=$ DLCD_v2-1_20140101-20151231.tif

Input spatial reference $=\bar{G} C S$ WW $\bar{G} S \_1984$

Output file path =

GDB name = Australia_temp.gdb

Input area type $=$ Middle

Input area centre lon/lat $=132.504595,-28.266069$

Input area latitude $\mathrm{max} / \mathrm{min}=-10.000000,-45.004798$

Input area size $(\mathrm{km}$ squared $)=16985010.34$

Input area extent group $=\mathrm{N} / \mathrm{A}$ 
Input area standard parallels for conic projections $=\mathrm{N} / \mathrm{A}$

Number of points selected for distortion assessment $=166$

Distortion assessment weights: Distance $=0$; Area $=1$; Shape $=0$

Distortion assessment results (listed in order of least Combined Index):

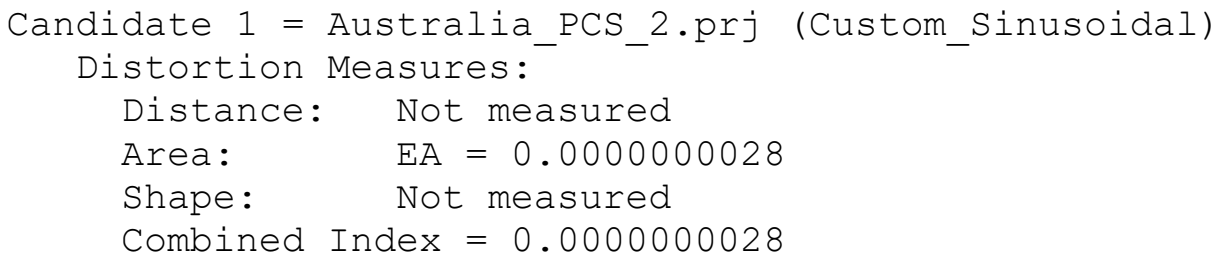

- When selecting Thematic Vector / Raster or Geospatial Analysis (Area) purposes the distortion assessment is based only on area distortion. In all cases the combined index result is almost exactly zero and the ranking order is effectively arbitrary. Therefore, the user should view each option graphically before making their selection decision using qualitative reasons.

- Areas smaller than World or Hemisphere size - the user is advised that in many situations an additional sensible choice can be the reference system used by the local or national mapping agency, or in global use such as the UTM system. This is especially true if certain datasets to be used in the project are already referenced to that system. Note that these systems mostly use conformal map projections such as Transverse Mercator and Lambert Conformal Conic.

\section{Navigation Routes (Geodesic) from Miami to Tokyo}

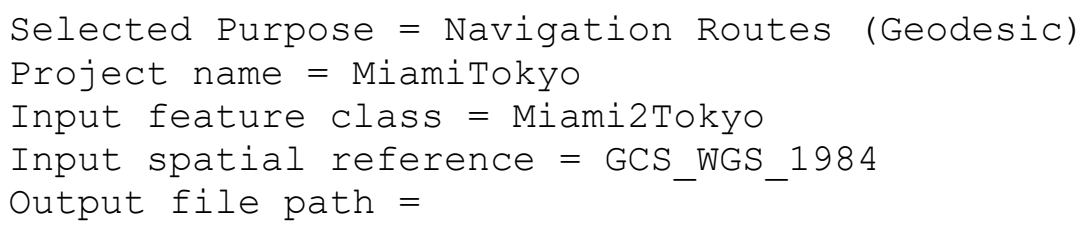




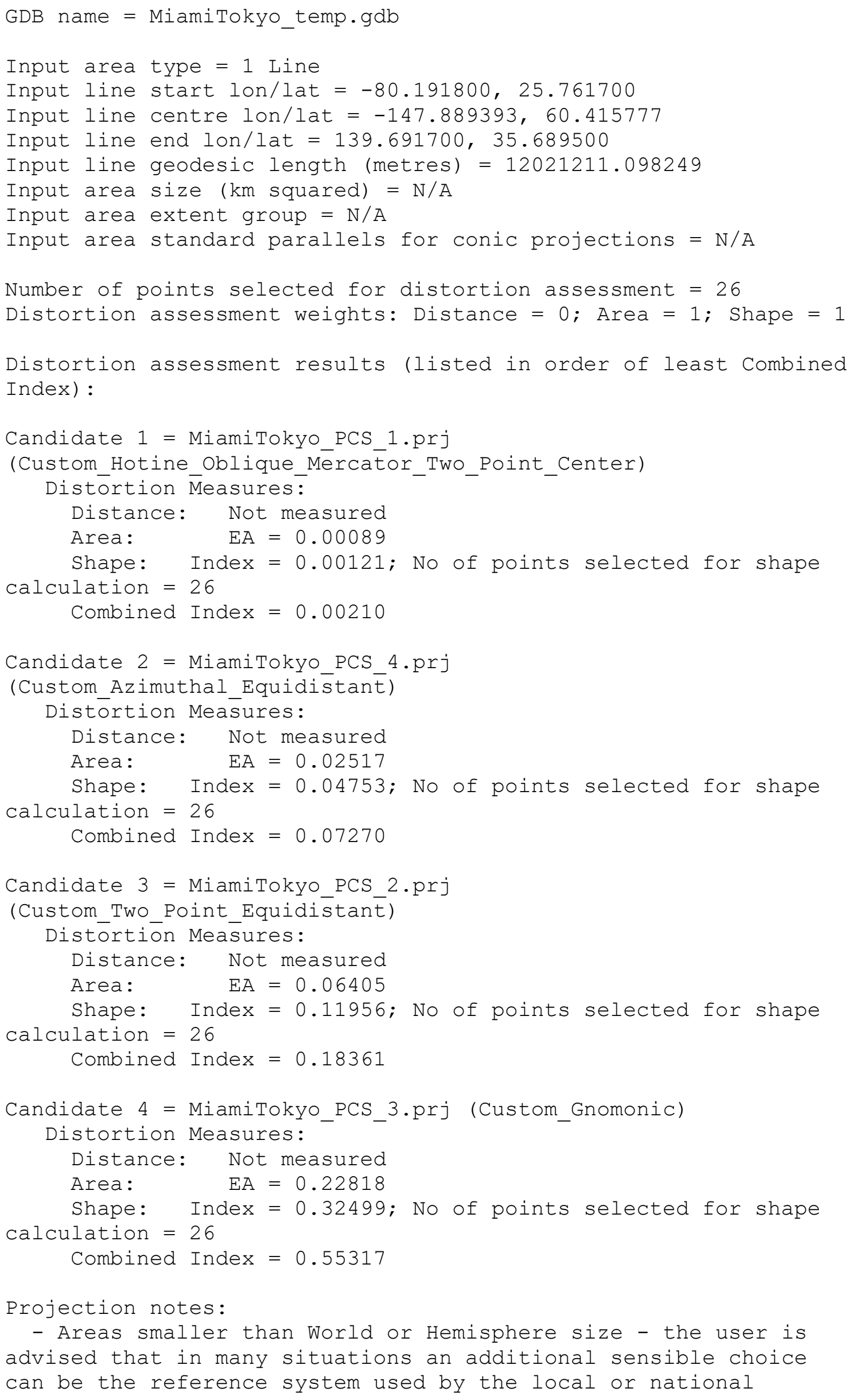

- Areas smaller than World or Hemisphere size - the user is advised that in many situations an additional sensible choice can be the reference system used by the local or national 
mapping agency, or in global use such as the UTM system. This is especially true if certain datasets to be used in the project are already referenced to that system. Note that these systems mostly use conformal map projections such as Transverse Mercator and Lambert Conformal Conic. 
Table 1. Description of purposes included in the projection selection process.

\begin{tabular}{|c|c|}
\hline Purpose & Description \\
\hline General Reference & Location of geographical features, e.g. atlas maps, topographical maps. \\
\hline Thematic Vector & $\begin{array}{l}\text { Geographical distribution of phenomena rather than location, e.g. } \\
\text { statistical maps. }\end{array}$ \\
\hline Thematic Raster & $\begin{array}{l}\text { Geographical distribution of phenomena based on raster data, e.g. } \\
\text { land-use/land-cover. }\end{array}$ \\
\hline $\begin{array}{l}\text { Geospatial Analysis } \\
\text { (Distance) }\end{array}$ & $\begin{array}{l}\text { Analysis based on accurate measurement of distances between } \\
\text { features, e.g. spatial distribution, nearest neighbor, spatial } \\
\text { autocorrelation, clustering, and geostatistical methods such as Inverse } \\
\text { Distance Weighting. }\end{array}$ \\
\hline $\begin{array}{l}\text { Geospatial Analysis } \\
\text { (Area) }\end{array}$ & $\begin{array}{l}\text { Analysis based on accurate measurement of the area of an object, e.g. } \\
\text { population density. }\end{array}$ \\
\hline $\begin{array}{l}\text { Navigation Routes } \\
\text { (Geodesic) }\end{array}$ & $\begin{array}{l}\text { Navigation based on travelling the shortest distance between two } \\
\text { locations, also referred to as Great Circle navigation. }\end{array}$ \\
\hline $\begin{array}{l}\text { Navigation Routes } \\
\text { (Loxodrome) }\end{array}$ & $\begin{array}{l}\text { Navigation primarily for maritime use based on sailing a constant } \\
\text { bearing between two locations, also referred to as Rhumb-Line } \\
\text { navigation. }\end{array}$ \\
\hline Ranges of Activity & $\begin{array}{l}\text { Visualization of phenomena distance from single/multiple source } \\
\text { locations. }\end{array}$ \\
\hline Flow Patterns & $\begin{array}{l}\text { Display of symbolized arrows highlighting object movement between } \\
\text { locations, e.g. migration, commercial distribution, airline routes. }\end{array}$ \\
\hline World Index & $\begin{array}{l}\text { Global overlay of information on basic geographical outlines, e.g. time } \\
\text { zones, climate zones. }\end{array}$ \\
\hline
\end{tabular}

Table 2. Geographical footprint extent ratios.

\begin{tabular}{lcc}
\hline Country & Extent Ratio & Extent Category \\
\hline Chile & 0.18 & North-South \\
UK & 0.55 & North-South \\
France (mainland) & 0.95 & Equal \\
India & 0.96 & Equal \\
Australia & 1.08 & Equal \\
Canada & 1.19 & Equal \\
China & 1.19 & Equal \\
USA (conterminous) & 1.63 & East-West \\
Russia & 1.74 & East-West \\
\hline
\end{tabular}


Table 3. Distortion measures relevant to each purpose.

\begin{tabular}{lccc}
\hline Purpose & Distance & Area & Shape \\
\hline General Reference & 0 & 1 & 1 \\
Thematic Vector & 0 & 1 & 0 \\
Thematic Raster & 0 & 1 & 0 \\
Geospatial Analysis (Distance) & 1 & 0 & 0 \\
Geospatial Analysis (Area) & 0 & 1 & 0 \\
Navigation Routes (Geodesic) & 0 & 1 & 1 \\
Navigation Routes (Loxodrome) & 0 & 1 & 1 \\
Ranges of Activity & 1 & 0 & 0 \\
Flow Patterns & 0 & 1 & 1 \\
World Index & 0 & 1 & 1 \\
\hline
\end{tabular}


Figure 1. Example projection selection diagrams for three use cases, showing the

\section{categories of footprints.}
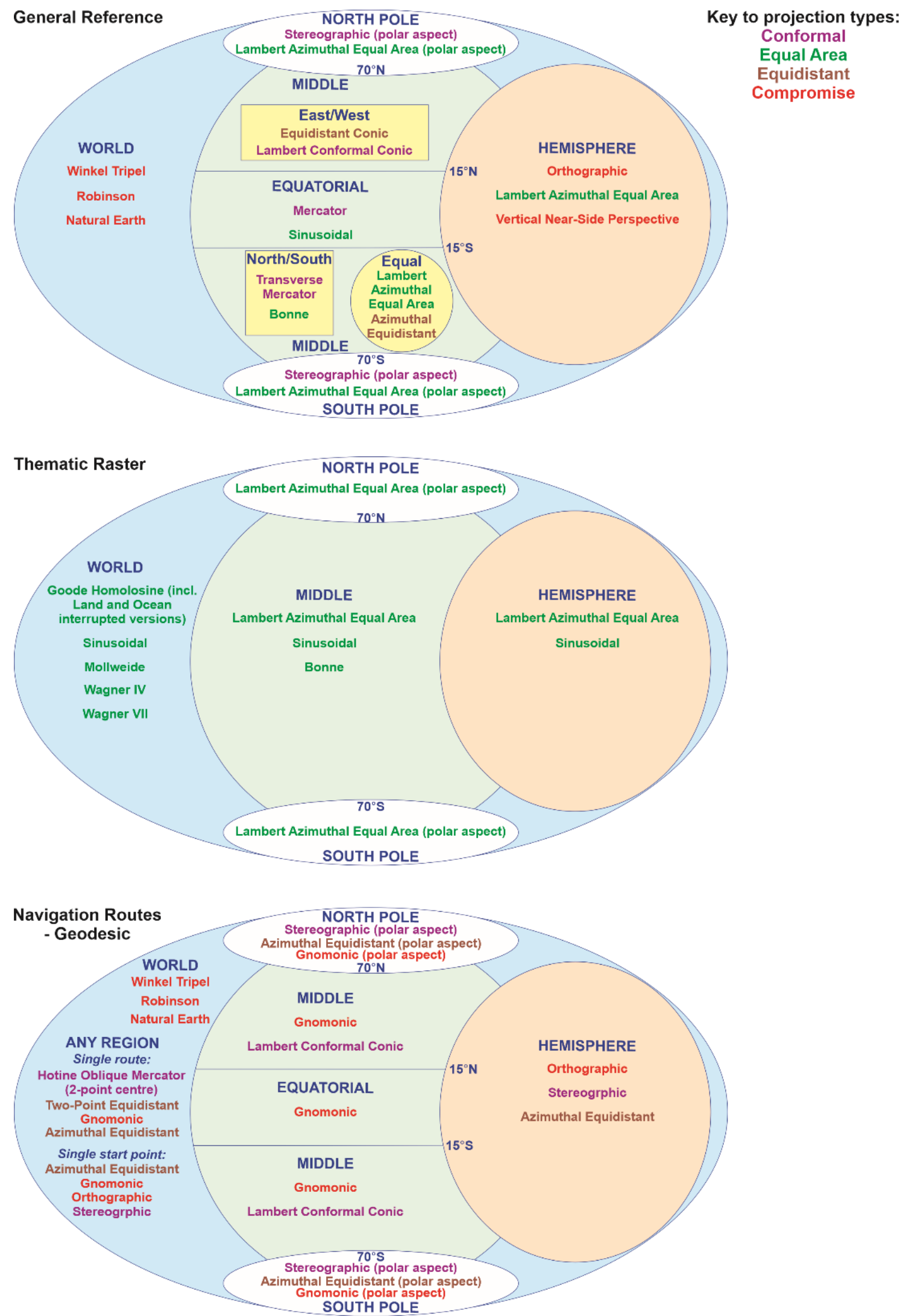
Figure 2. Automated Projection Selection ArcMap Python Add-in toolbar.

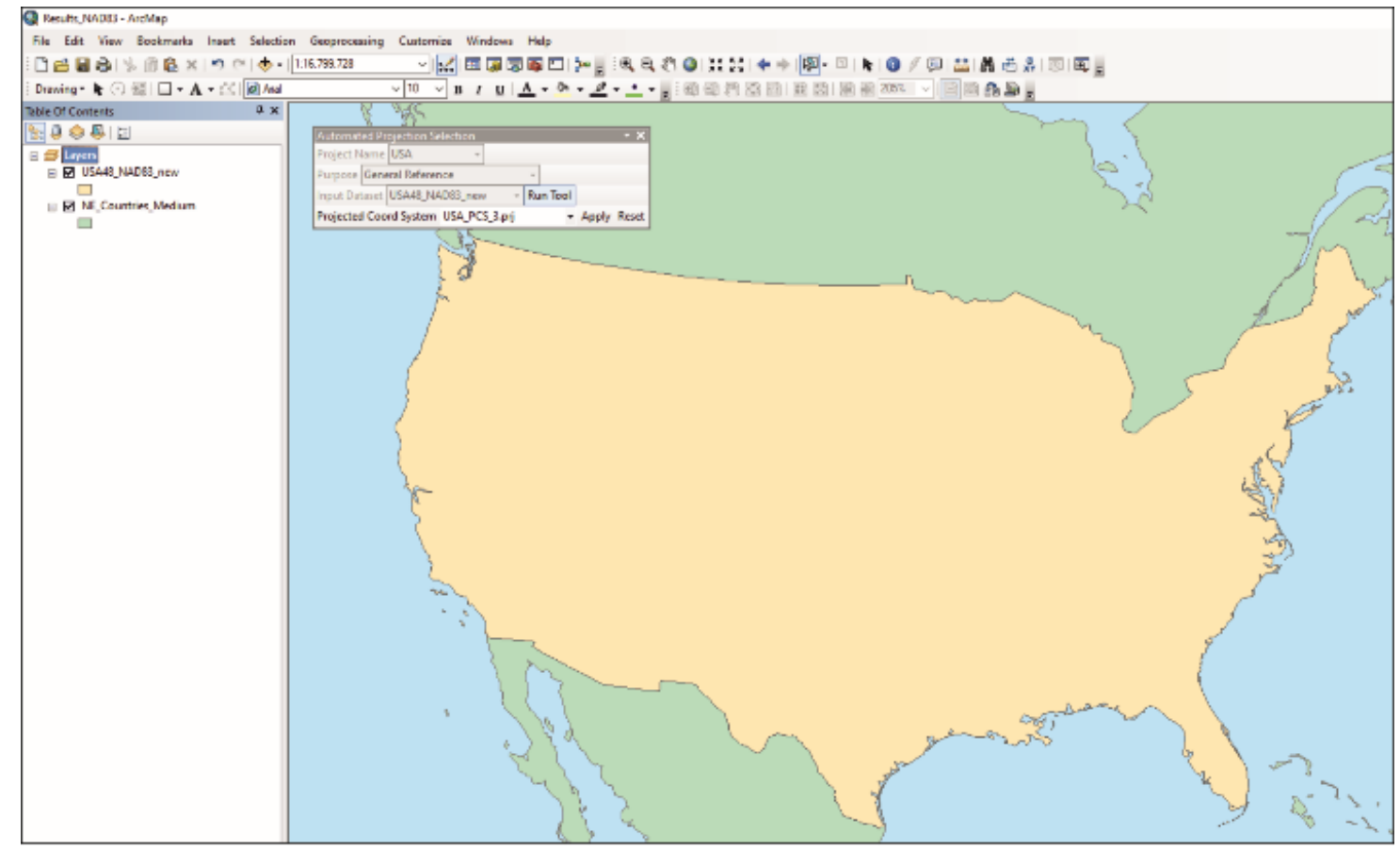

Figure 3. Conterminous United States using: a) Equidistant Conic candidate projection; and b) Albers Equal-Area Conic projection for comparison.

a)

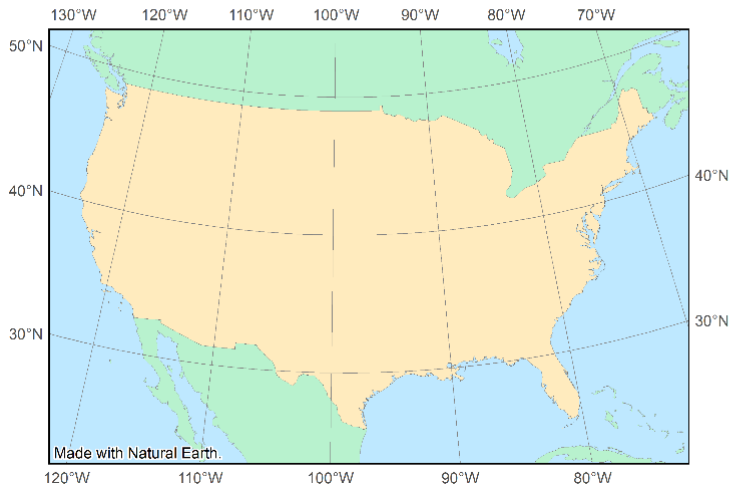

b)

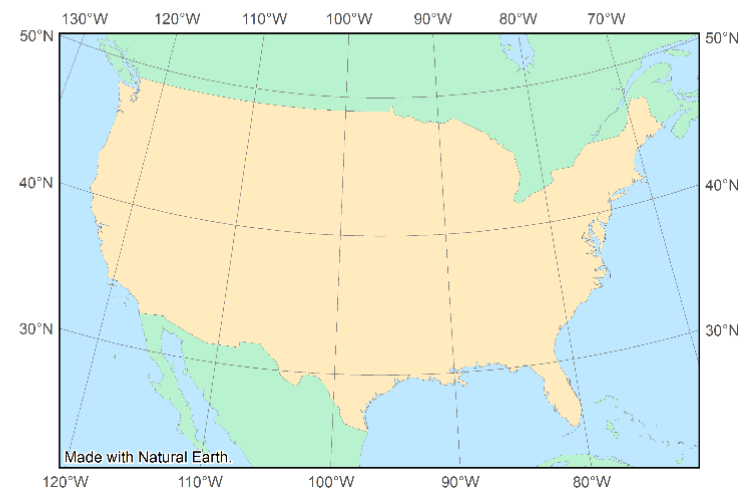


Figure 4. Australia Land Cover Dataset using: a) Sinusoidal candidate projection; and b) Lambert Conformal Conic projection for comparison.

a)

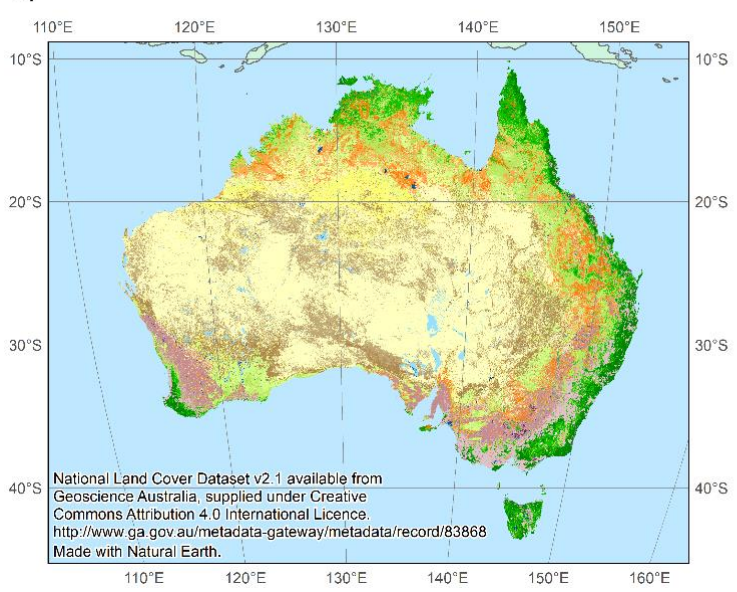

b)

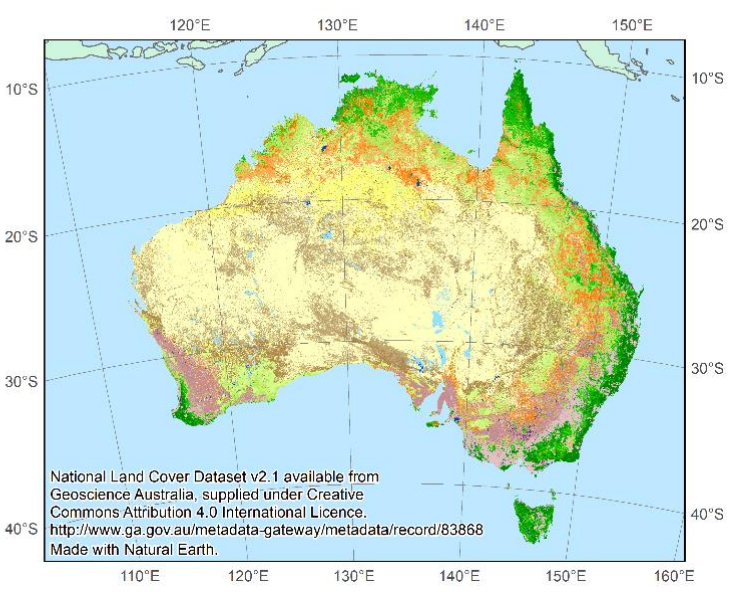

Figure 5. Comparison Projection Wizard results for Australia using Equal-area

Property.

(2)

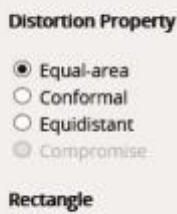

North: $10^{\circ} 00^{\circ} 00^{\prime} \mathrm{S}$

South: $45^{\circ} 00^{\circ} 00^{\circ} \mathrm{S}$

East $155^{\circ} 00^{\circ} 00^{\circ} \mathrm{E}$

West $112^{\circ} 00^{\circ} 00^{\circ} \mathrm{E}$

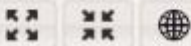

o 2017 earansintis
Projection Wizard
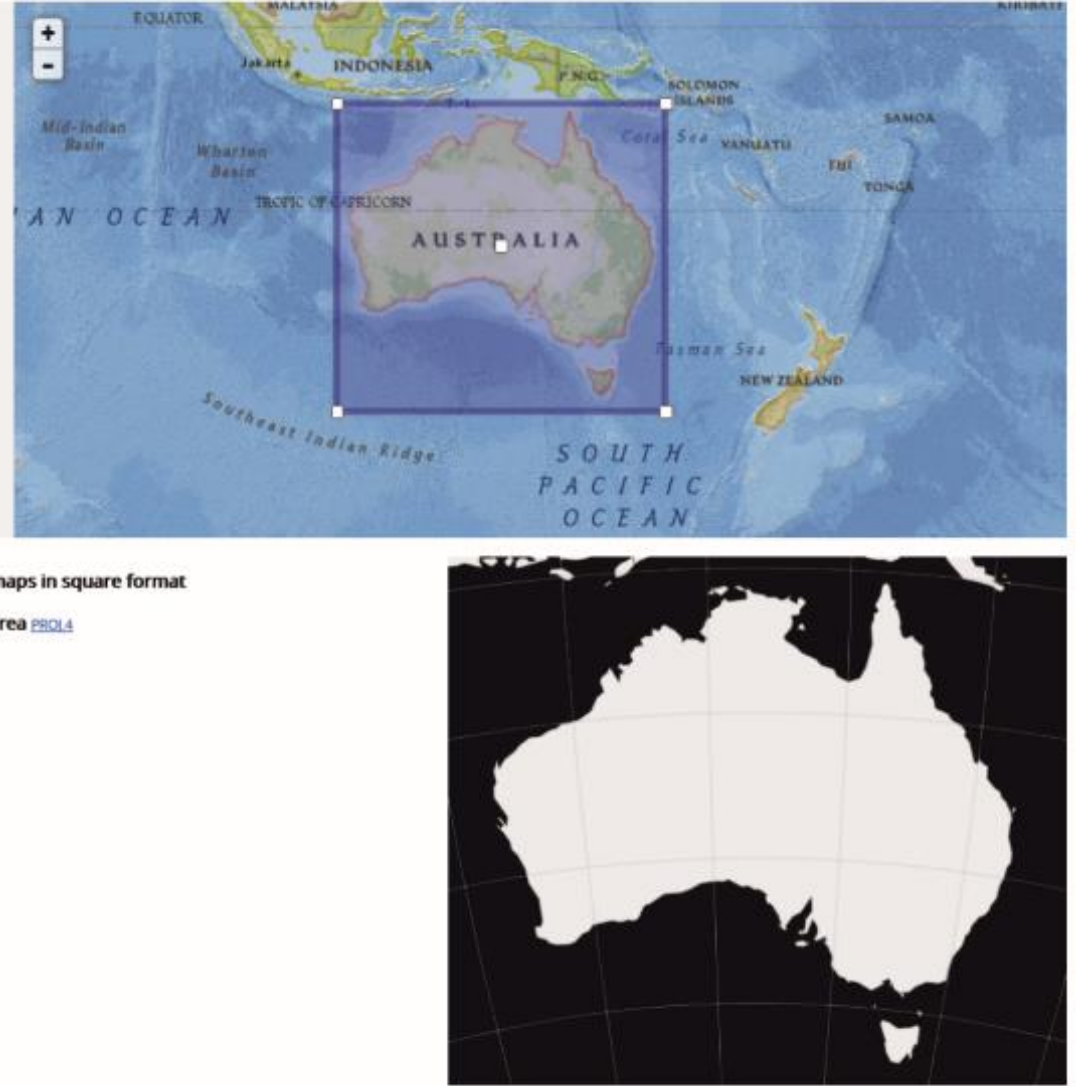

Oblique Lambert azimuthal equal-area pach

Center latitude: $27^{\circ} 30^{\circ} \mathrm{S}$

Center longitude: $133^{\circ} 30^{\prime} \mathrm{E}$ 
Figure 6. Miami to Tokyo route using: a) Hotine Oblique Mercator candidate projection; and b) Mercator projection for comparison.

a)

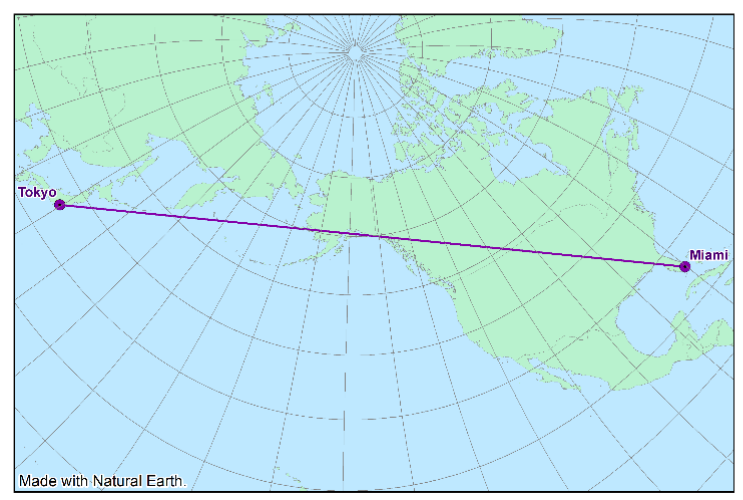

b)

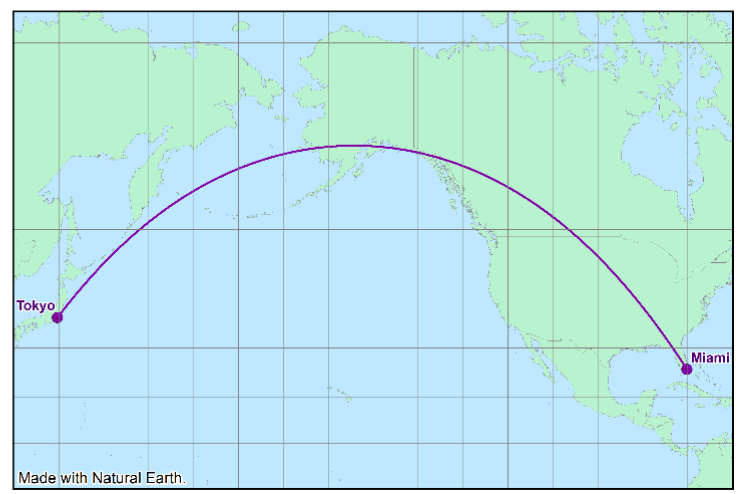

